\title{
Jackson Park Hospital Green Building Medical Center
}

Type of Report: Final

\author{
Report Period: October 1, 2009 To December 31, 2009 \\ Principal Authors: William Dorsey, M.D. \\ Nelson Vasquez
}

Date Report Was Issued: May, 2010

D.O.E. Award Number: DE-FG26-08NT01985

Submitted By: Nelson Vasquez

Vice president Finance

Jackson Park Hospital Foundation

7531 Stony Island

Chicago, IL 60649

Disclaimer;

This report was prepared as an account of work sponsored by an agency of the United States Government. Neither the United States Government nor any agency thereof, nor any of their employees, makes any warranty, express or implied, or assumes any legal liability or responsibility for the accuracy, completeness, or usefulness of any information,

apparatus, product, or process disclosed, or represents that its use would not infringe privately owned rights. Reference herein to any specific commercial product, process, or service by trade name, trademark, manufacturer, or otherwise does not necessarily constitute or imply its endorsement, recommendation, or favoring by the United States Government or any agency thereof. The views and opinions of authors expressed herein do not necessarily state or reflect those of the United States Government or any agency thereof. 


\section{FINAL REPORT ON PROJECT COMPLETENESS}

Jackson Park Hospital Green Building Medical Center

\section{EXECUTIVE SUMMARY}

\section{Award No. DE-FG26_08NT01985}

Jackson Park Hospital completed the construction of a new Medical Office Building on its campus this spring. The new building construction has adopted the City of Chicago's recent focus on protecting the environment, and conserving energy and resources, with the introduction of green building codes. Located in a poor, inner city neighborhood on the South side of Chicago, Jackson Park Hospital has chosen green building strategies to help make the area a better place to live and work.

The new green building houses the hospital's Family Medicine Residency Program and Specialty Medical Offices. The residency program has been vital in attracting new, young physicians to this medically underserved area. The new outpatient center will also help to allure needed medical providers to the community. The facility also has areas designated to women's health and community education. The Community Education Conference Room will provide learning opportunities to area residents. Emphasis will be placed on conserving resources and protecting our environment, as well as providing information on healthcare access and preventive medicine.

The new Medical Office Building was constructed with numerous energy saving features. The exterior cladding of the building is an innovative, locally-manufactured precast concrete panel system with integral insulation that achieves an R-value in excess of building code requirements. The roof is a "green roof" covered by native plantings, lessening the impact solar heat gain on the building, and reducing air conditioning requirements. The windows are low- $\mathrm{E}$, tinted, and insulated to reduce cooling requirements in summer and heating requirements in winter. The main entrance has an air lock to prevent unconditioned air from entering the building and impacting interior air temperatures. Since much of the traffic in and out of the office building comes from the adjacent Jackson Park Hospital, a pedestrian bridge connects the two buildings, further decreasing the amount of unconditioned air that enters the office building. The HVAC system has an Energy Efficiency Rating 29\% greater than required. No CFC based refrigerants were used in the HVAC system, thus reducing the emission of compounds that contribute to ozone depletion and global warming. In addition, interior light fixtures employ the latest energy-efficient lamp and ballast technology. Interior lighting throughout the building is operated by sensors that will automatically turn off lights inside a room when the room is unoccupied. The electrical traction elevators use less energy than typical elevators, and they are made of 95\% recycled material. Further, locally manufactured products were used throughout, minimizing the amount of energy required to construct this building.

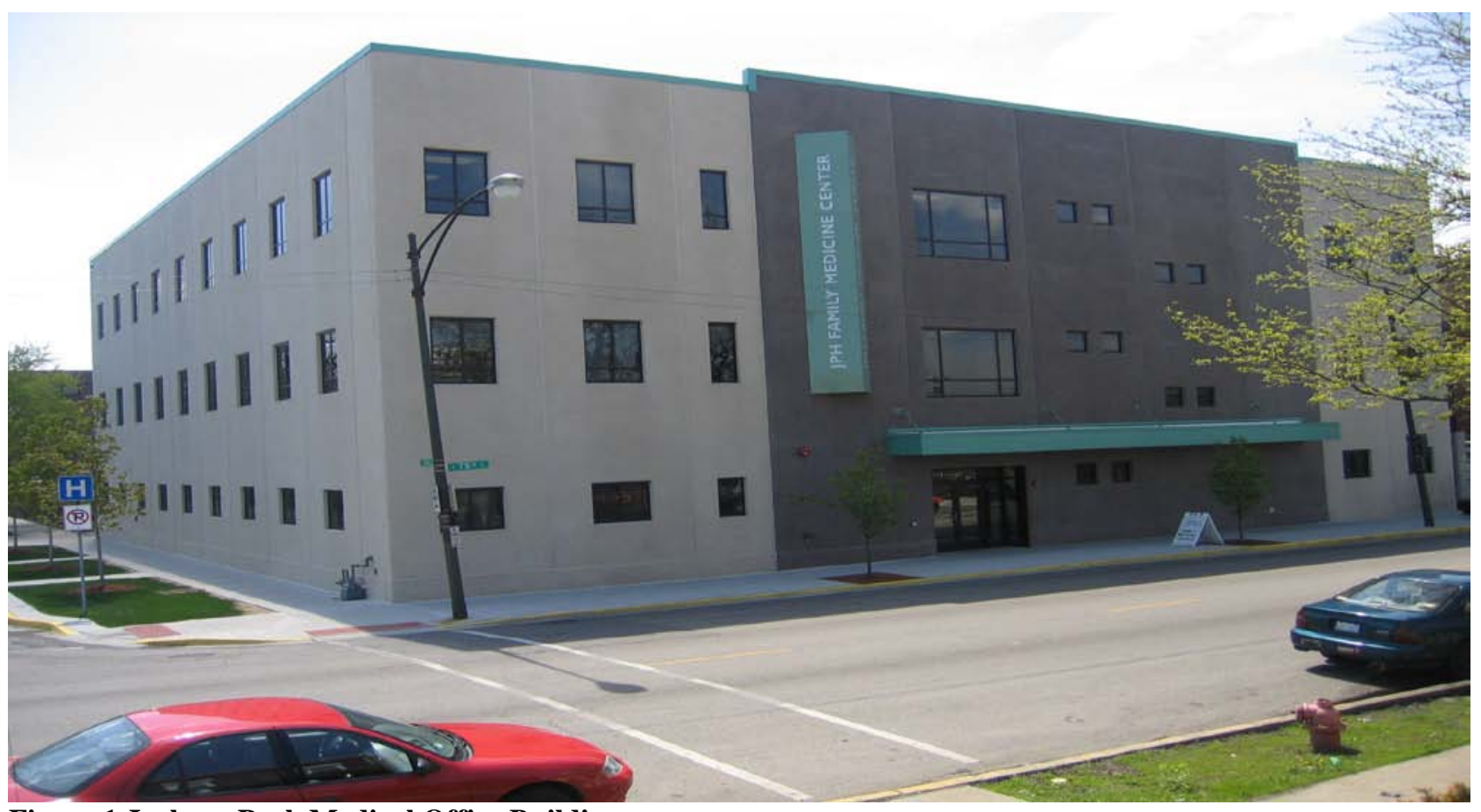

Figure 1 Jackson Park Medical Office Building 


\section{PROJECT OBJECTIVES}

The primary objective was to construct a 30,000 square foot medical office building on the Jackson Park Hospital campus that would comply with newly adopted City of Chicago green building codes focusing on protecting the environment and conserving energy and resources. The energy saving systems demonstrate a state of the-art whole-building approach to energy efficient design and construction. The energy efficiency and green aspects of the building contribute to the community by emphasizing the environmental and economic benefits of conserving resources. The building highlights the integration of Chicago's new green building codes into a poor, inner city neighborhood project and it is designed to attract medical providers and physicians to a medically underserved area.

\section{PROJECT STATUS}

The construction of the medical office building is $100 \%$ complete. The building is fully occupied and operational and it was granted a certificate of occupancy on June 26, 2009.

Included in the project were a number of environmental and sustainability goals. Jackson Park Hospital implemented a strategy to take advantage of the City of Chicago Green Building Permit program, which expedited the permitting process and fee waivers. This strategy also required a LEED Silver Certification. The project saved more than \$32,000.00 in project review fees by adopting this strategy. In addition, the project permitting process timeline was shortened by approximately 120 days. A number of design features were incorporated as project tasks to meet the project objectives: Composite insulated exterior panels, a connector between the hospital and new medical office building, low-E windows, high efficiency HVAC system, an energy efficient green roof, energy efficient passenger elevators, and high efficiency lighting. These tasks are highlighted below. Jackson Park Hospital went beyond its stated objective by including other green design features such as utilizing low-flow plumbing fixtures, low VOC (volatile organic compounds) products, agrifiber cores for doors and casework, utilizing local and recycled materials, and implementing a recycling container program throughout the building. By implementing these features, Jackson Park Hospital exceeded its LEED Silver Certification goal and was awarded a LEED Gold Certification by the Green Building Certification Institute. Beyond the incentives for a green building, the hospital recognized its responsibility to make as little negative impact on the environment as possible with this project.

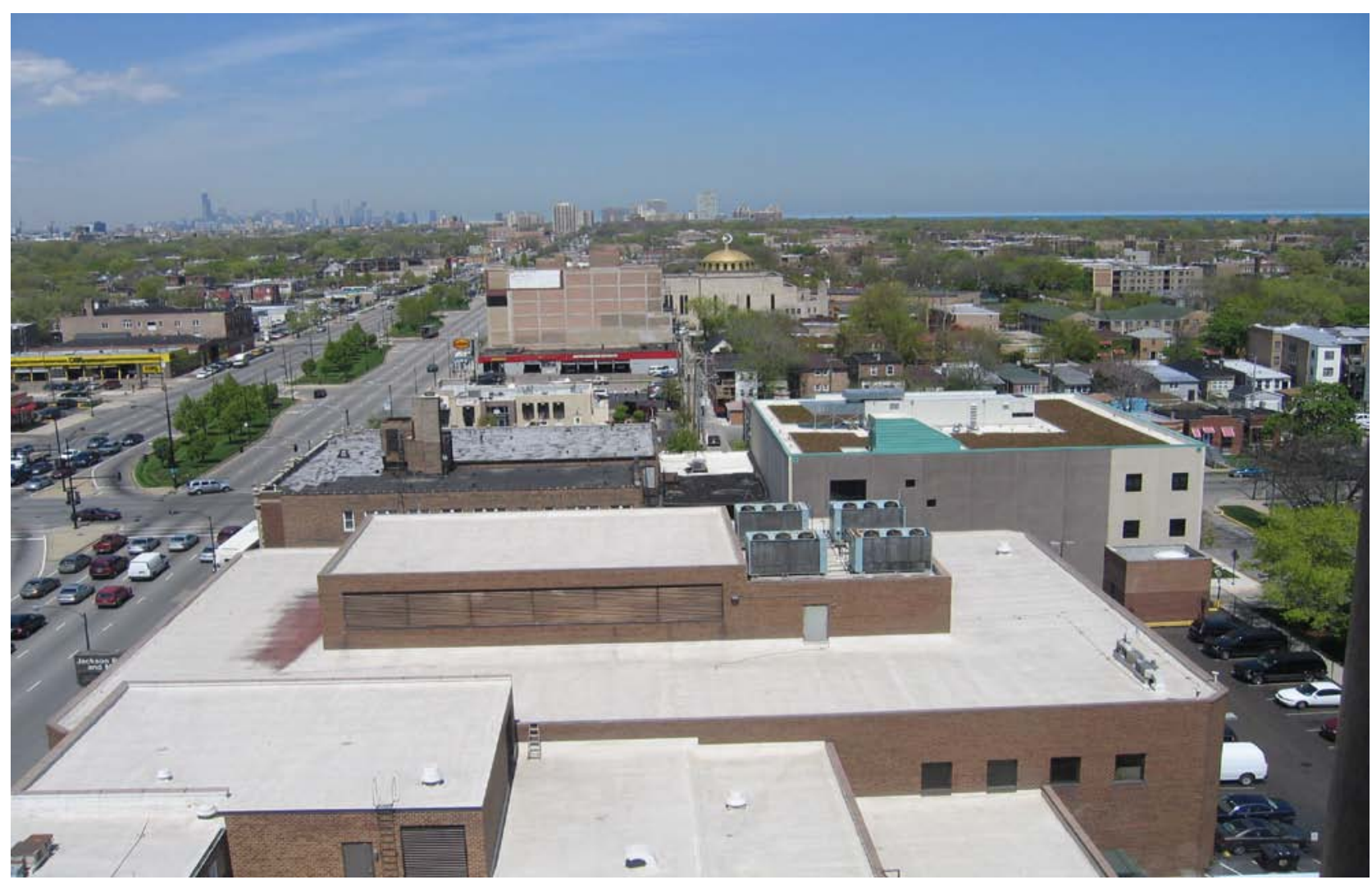




\section{Figure 2 Medical Office Building located on the south side of Chicago, IL TASKS PERFORMED}

\section{Task 1.0 -Energy Efficiency Exterior Panels}

The building exterior panel system was procured and installed in accordance to the final engineered plans and specifications as approved by the project architect. All load calculations were verified by the structural engineer. Shop drawings were developed by the panel manufacturer and submitted for approval to the project architect and structural engineer prior to erection. All panels were fabricated to meet the specifications for R-value and thermal performance. Panel attachment design was reviewed for performance. All connections and fastening methods were confirmed by the project architect and an independent third party testing consultant for conformity to the project plans and specifications. Regular construction meetings and updates on the panel erection were documented on a weekly basis during the erection and construction of the panels.

The project design team including the project architect and structural engineer coordinated the final installation with the general contractor and installer. The specified and approved panel system is attached to the building superstructure in accordance to approved plans. The panel system meets all specifications for energy efficiency performance required by the project.

The building exterior cladding utilizes an innovative, locally manufactured pre-cast concrete panel system with integral insulation that added to overall energy efficiency. The concrete panels are 9" to 11" thick. The resulting R-value and thermal performance created an overall energy and operating savings in excess of thirty percent (30\%).

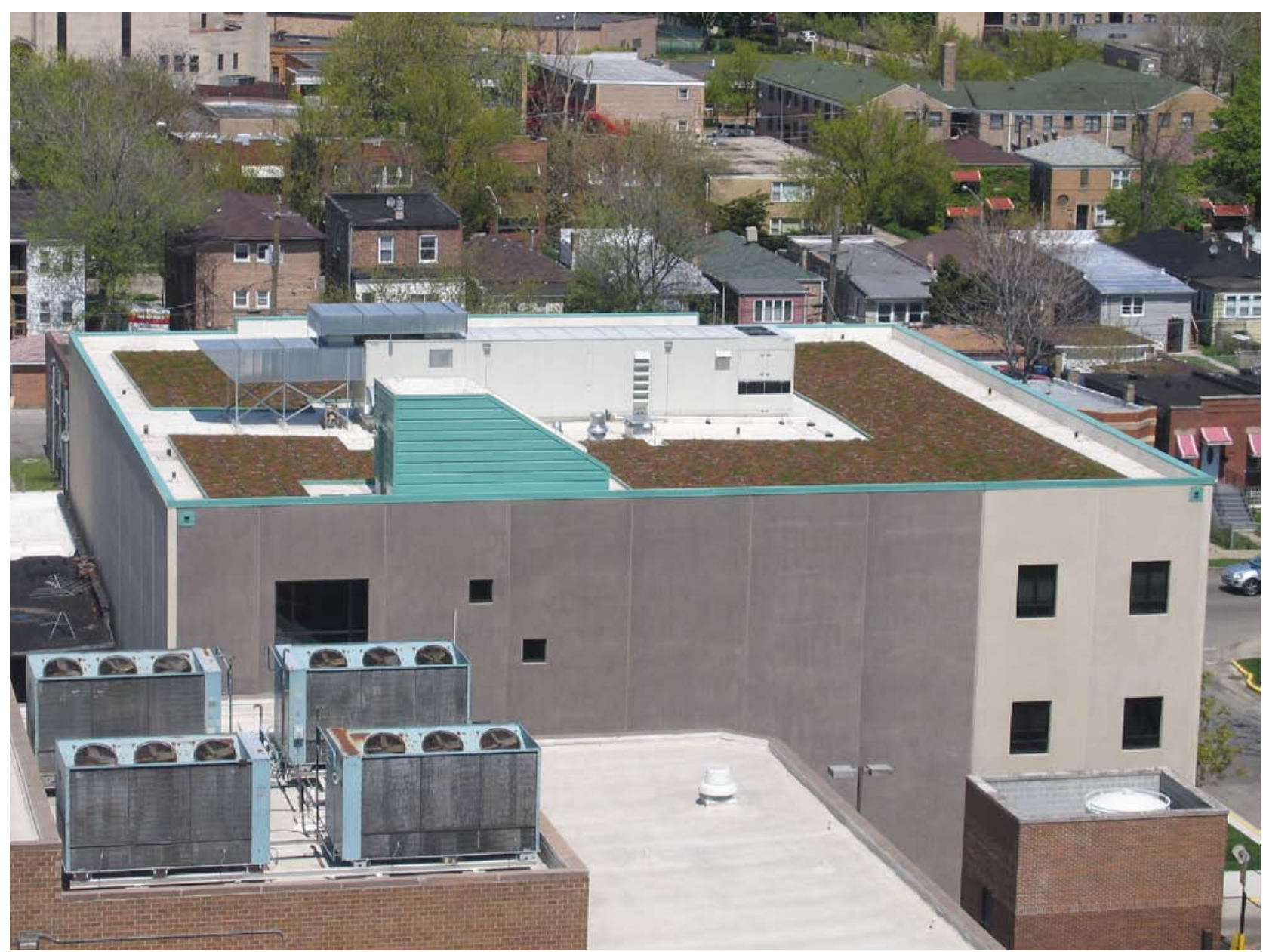

Figure 3 The exterior panel system of the medical office building 


\section{Task 2.0 - Connector Bridge Between the Medical Office Building and Hospital Building}

Significant traffic in and out of the medical office building is anticipated to come from the adjacent Jackson Park Hospital. A pedestrian bridge was constructed connecting the two buildings to decrease the amount of unconditioned outside air that could enter the medical office building. Additionally, the connector created an efficient means of ingress and egress between the facilities, reducing travel time and increasing productivity of the physicians and program residents.

The connector bridge has a steel structure and utilizes low-E glass and glazing. The roof is a matching white EDPM white membrane. The exterior incorporates a metal cladding with high $\mathrm{R}$ value insulation. The interior is finished with acoustical ceiling tile, and low energy lighting. The bridge is conditioned with heating and air conditioning from the main system. The HVAC has a single VAV zone controlled by the building automation system.

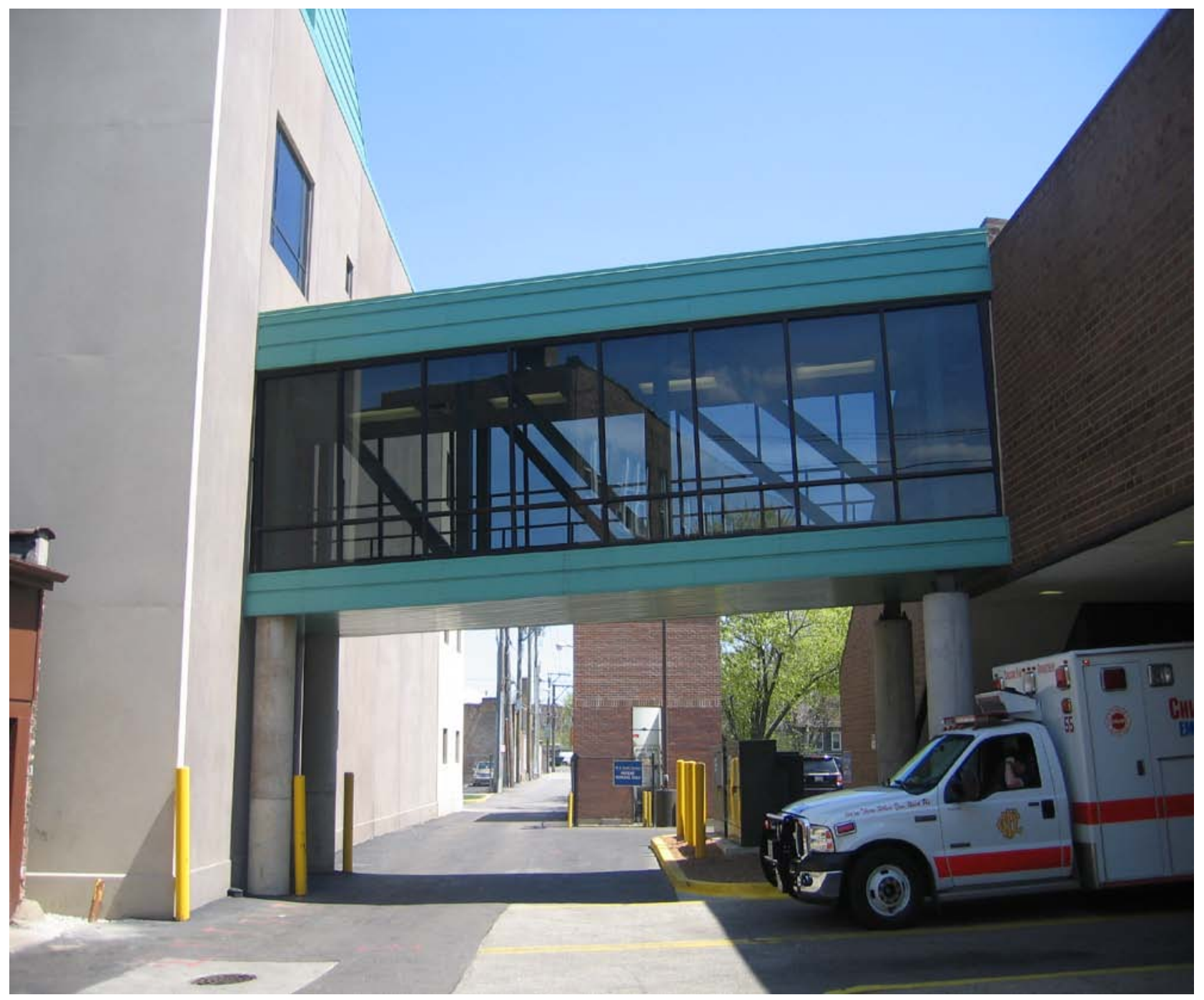

Figure 4 The connector bridge between the new medical office building and the hospital 


\section{Task 3.0 - Energy Efficient Windows}

Energy efficient windows and storefront systems were installed in the medical office building to improve overall building energy performance. The windows and storefront are low-E and tinted to reduce cooling requirements in summer and heating requirements in winter.

All aluminum framing for windows and storefront system were designed and specified to meet required structural performance, thermal movements, air infiltration, wind requirements, water penetration, condensation resistance, and thermal conductance factors. Energy efficient, low-E glazing, tinting, and 1-inch insulation were used to meet the required "U" values, solar heat gain coefficients and solar optical properties.

The low-E insulating glass has a window-to-wall ratio of 7\% (excluding the connector bridge).

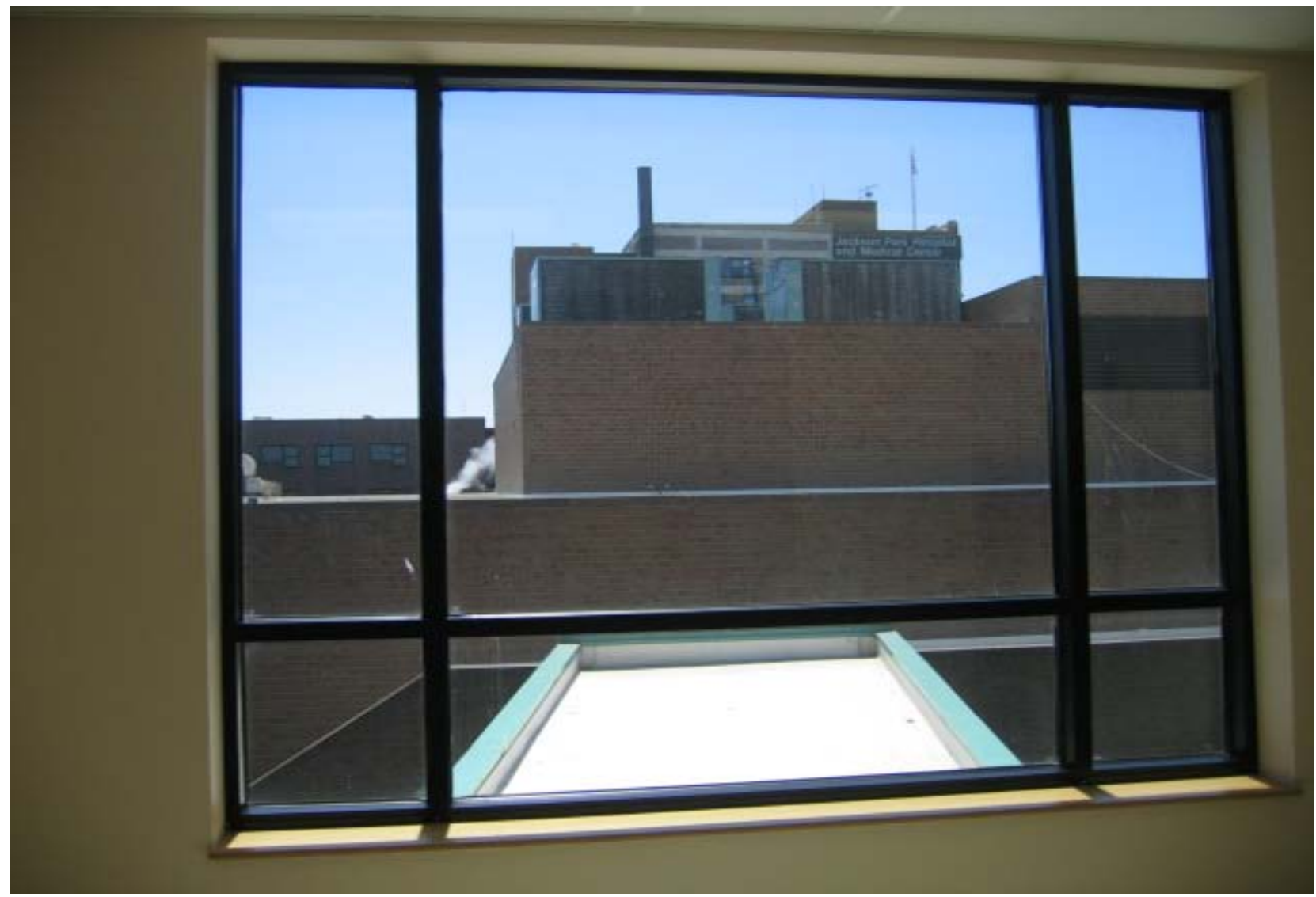

Figure 5 Low-E window system 


\section{Task 4.0 - Efficient HVAC System}

The building will be occupied daily and year round, except Sunday and holidays. Maximum capacity for the building was calculated at 202 occupants. The building will be heated to 70 degrees during the day and 53 degrees during the night in winter, and cooled to 75 degrees during the day and 83 degrees during the night in the summer. A minimum of 50 CFM will be provided for each room.

The medical office building's heating ventilation and cooling (HVAC) system was designed to meet or exceed the Chicago Building Code energy efficiency requirements and ASHRAE 90.1-2004. In addition, the energy performance was optimized by producing energy savings of over $30 \%$ of a baseline case. Design features contributing to energy optimization included the installation of a roof mounted air handling unit. The supply fan has the capacity of 31,300 CFM, and the exhaust fan has a capacity of 26,580 CFM. Heating is provided by a gas fired heat exchanger with the capacity of $656.8 \mathrm{MBH}$ and an efficiency rating of 83. Cooling is provided by a water-cooled evaporative condenser with a total capacity of 883.6 MBH and an EER of 12.9. The air handling unit includes an energy recovery wheel and air measuring stations to monitor supply air, exhaust air, and outdoor air flow.

Rooms are heated, cooled, and ventilated through ceiling diffusers by way of insulated ductwork and VAV terminal units, with roughly 20 VAV zones per floor. Return air is exhausted through the plenum space above the acoustic ceiling tile system. Demand Ventilation Control is used to keep carbon dioxide levels in rooms at accountable levels. Toilet rooms, janitor closets, soiled linen, and soiled waste rooms have exhaust fans. Stairwells are not served by the HVAC system, but do have electrical heaters.

The mechanical systems are managed and monitored with a fully integrated building automation system incorporating direct digital control. The automation system communicates with all necessary building systems, and is accessible to building maintenance staff.

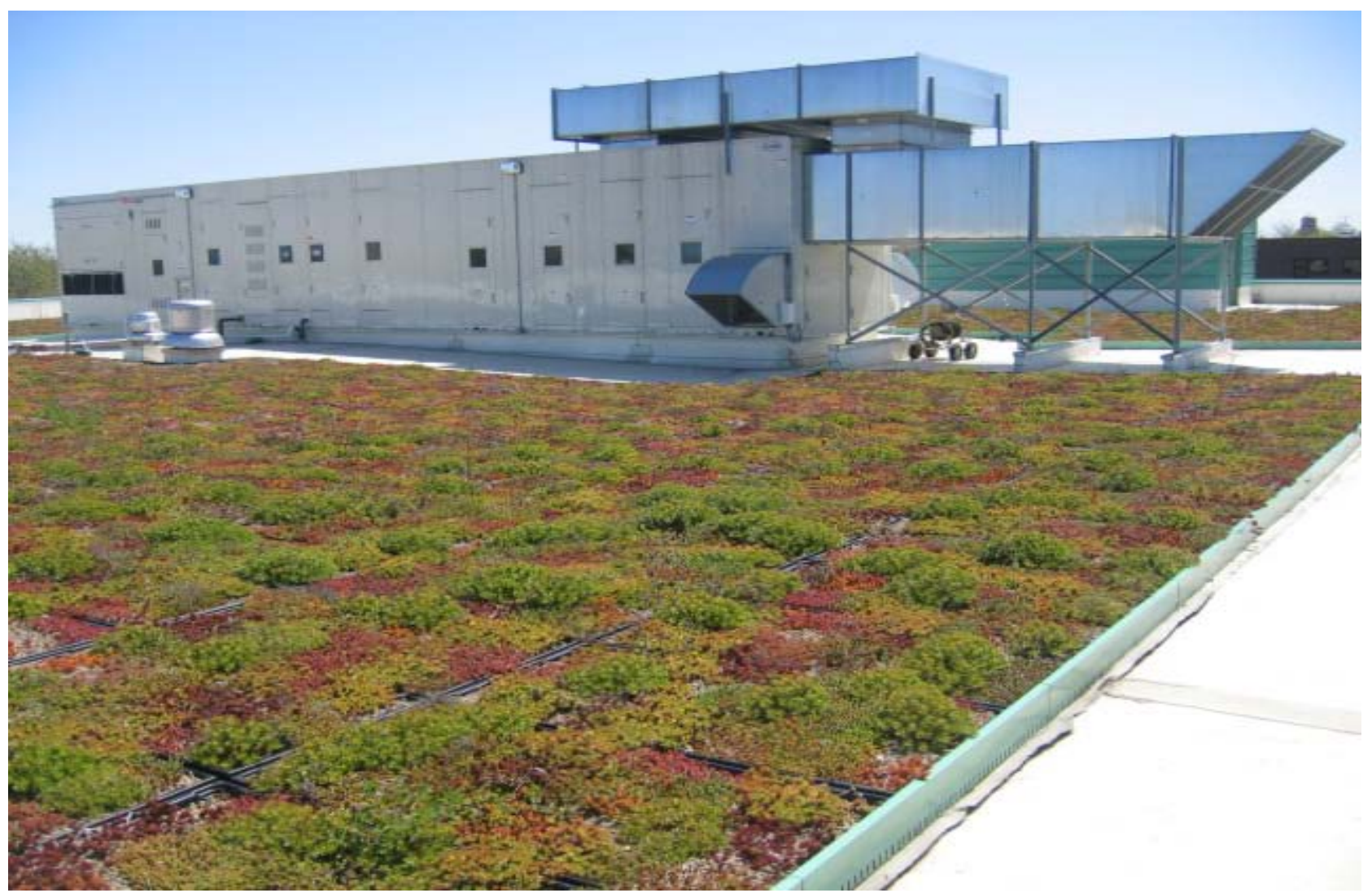

Figure 6 The high efficiency roof top unit and green vegetated roof 


\section{Task 5.0 - Energy Efficient Green Roof}

An energy efficient roof system was installed that incorporates ground covers in a module tray system to lessen the impact of solar heat gain and conductive heat loss on the building, thereby reducing both air conditioning and heating load requirements. Additionally, the green roof reduces storm water runoff significantly.

An energy efficient green roof system conform to the performance requirements of the roofing energy performance and Solar Reflectance Index specifications in the Chicago Building Codes. The roofing material is a white 60 mil EDPM single-ply adhered membrane which was installed according with the manufacturer's warranty requirements.

Growth media and plant product are an engineered blend of inorganic and organic components based upon German FLL Guidelines modified so as to contain ecologically sustainable levels of organic content. Since the plant product is drought resistant, manual irrigation is rarely required. Pavers, edging, and plant modules were installed as specified and inspected for quality control by a manufacturer's representative.

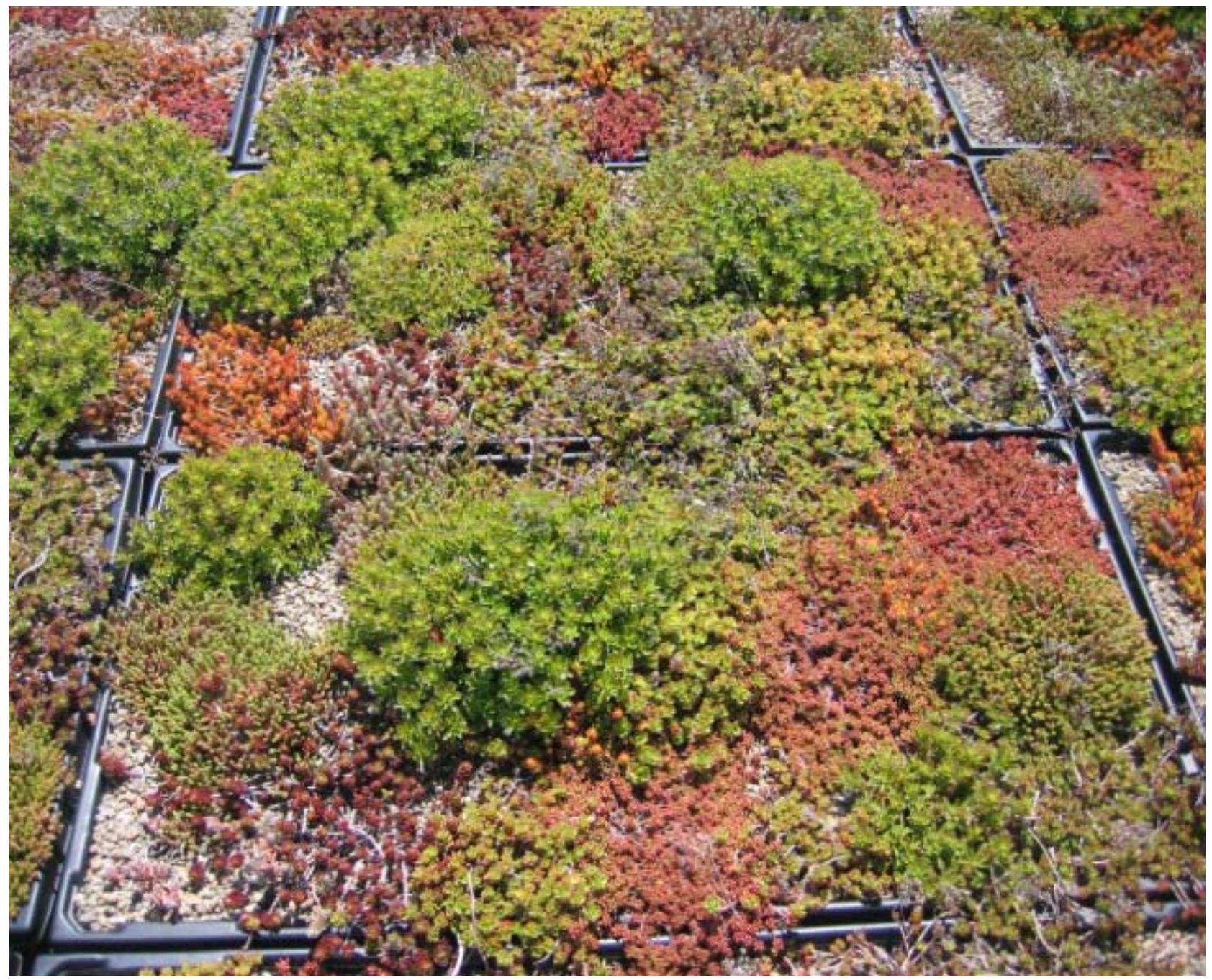

Figure 7 The green roof vegetation 


\section{Task 6.0 - Energy Efficient Passenger Elevators}

Energy efficient electric traction passenger elevators were installed. The passenger elevators vary energy usage based on passenger load.

The electric traction elevators are equipped with the following features for energy efficiency: Single-car auxiliary operation- in addition to primary operation this system features an automatic dispatching system that notifies the car when the load capacity exceeds 80 percent of rated capacity. Group auxiliary operation- in addition to primary operation the system features an automatic dispatching system of the loaded car when the car exceeds 80 percent of rated capacity and adds a loaded car bypass. The cars will only respond to car calls and not hall calls. An additional feature is added when cars are not required for response calls, they are parked with doors closed, distributed in predetermined zones throughout the building. One zone includes the main floor and adjacent floors; remaining floors are divided into equal zones.

The elevators are regulatory compliant to comply with ASME A 17.1, operations were tested for defects or system failure.

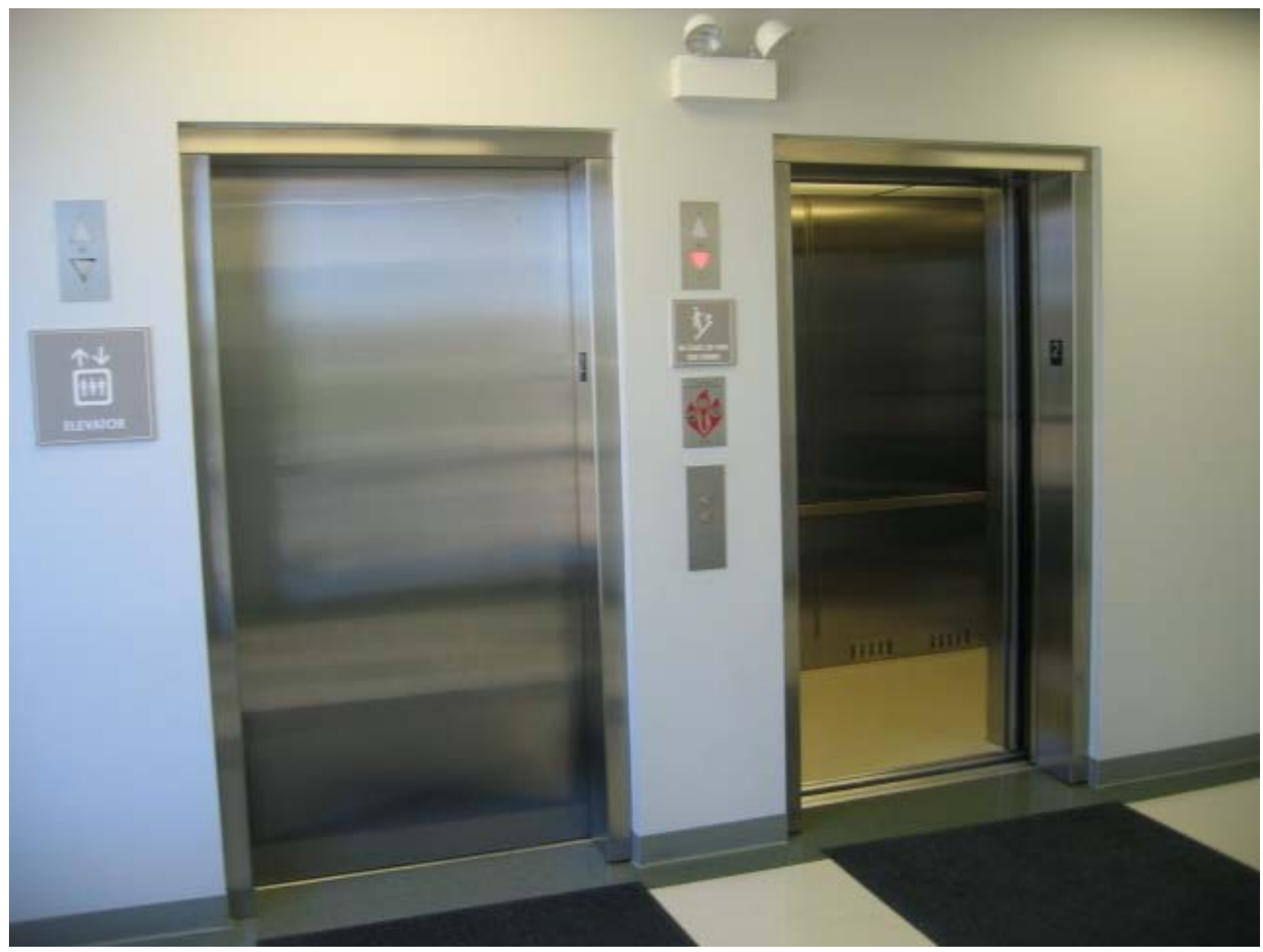

Figure 8 Passenger elevators 


\section{Task 7.0 -Energy Efficient Interior Lighting}

Interior light fixtures employing the latest energy-efficient lamp and ballast technology both F32T8 high efficiency 2x4 ceiling fixtures. Task lighting at workstations are provided for by under-cabinet fixtures with T5 lamps. The lighting fixtures meet the supply requirement not to exceed 1 watt per square foot.

Interior lighting in all offices are operated by bi-level switching to conserve energy. Also, all toilet and other room lighting are controlled by censors to automatically turn off when unoccupied. Additionally, all hallways have standard egress lights that are on continuously with the remaining fixtures switch operated. Interior recessed can -light fixtures are not used on this project due to their inefficiency and cost of operation. Emergency lighting and signage are provided by select ceiling fixtures with battery packs. All exit lights are LED type for efficiency.

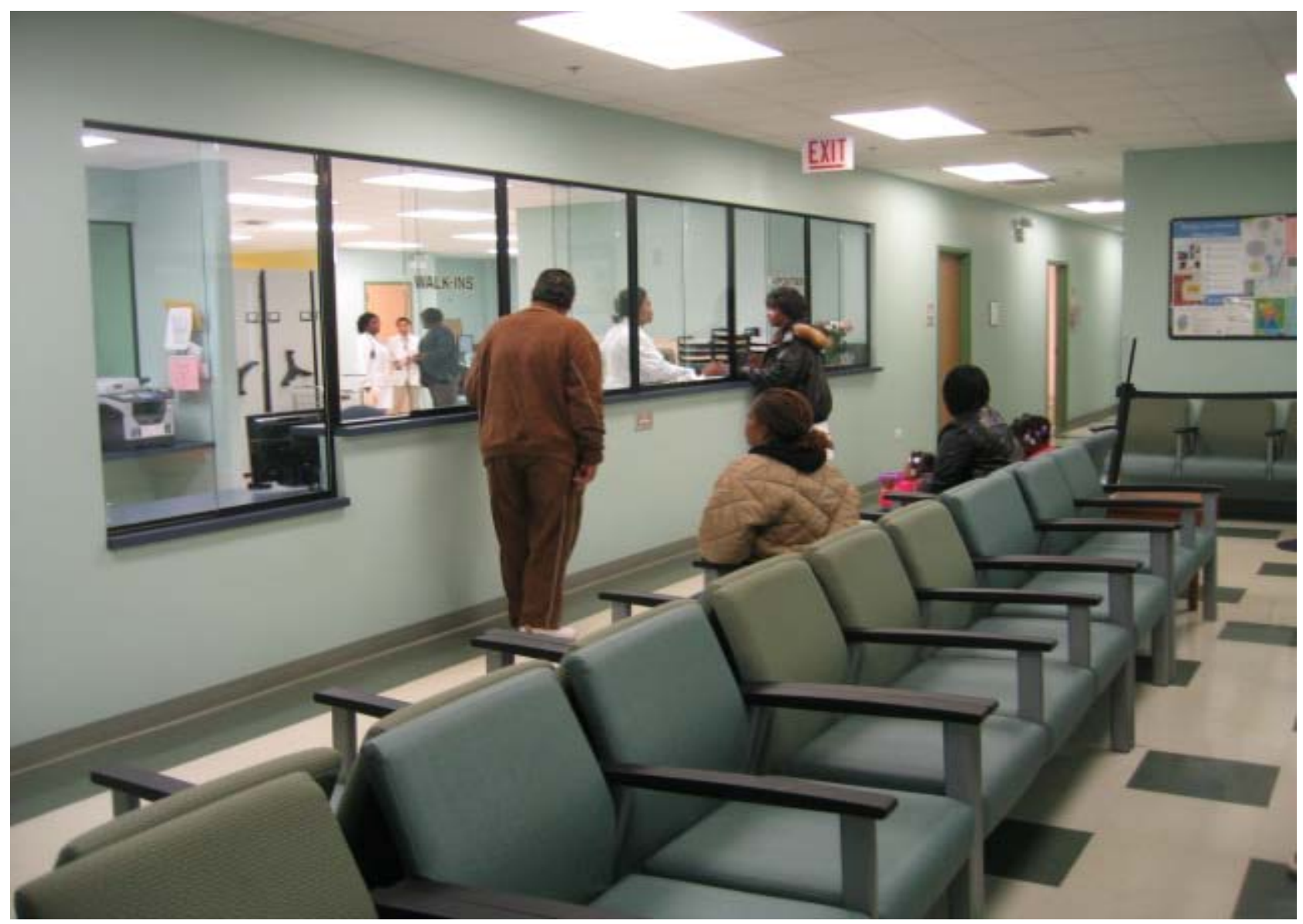

Figure 9 Interior lighting serves patient registration

\section{Other Narratives}

\section{Electrical Systems}

Power to the building is supplied by two separately metered service lines from a 500KVA utility transformer, one feeding a 2,000A main switchboard and one feeding a fire pump and its controller. The main switchboard feeds three panels on each floor, one for lighting (200A), one for outlets (200A) and one for mechanical equipment and elevators (600A). Loads for the 120/208V, 3-phase, 4-wire service will be: 107,100VA for lighting, 81,000VA for outlets, and 405,842VA for equipment, for a total of 593,492VA or 1,650A. Outlets are $120 \mathrm{~V}$ duplex outlets. 


\section{Plumbing Systems}

The plumbing systems serve six multiple-fixture toilet rooms, 11 small washrooms, 48 exam rooms, and 3 break rooms with sinks, and three janitor closets. An 8" water service line delivers water to a fire protection system and a duplex domestic water booster system with a flow rate of 90 GPM. a 120 -gallon electric water heater works with a thermostat-controlled recirculation pump to deliver hot water to the building.

Fire Protection System

The building has a Class 1, fully addressable fire alarm system that will communicate with all necessary building systems. The building has a sprinkler system that meets all local and national codes.

\section{The Community Education and Conference Room}

The community conference room will serve as an educational facility for the community. Emphasis will be placed on topics about conserving resources and protecting the environment. Healthcare issues and preventive medicine are other subjects that will be shared with the community by way of educational programs.

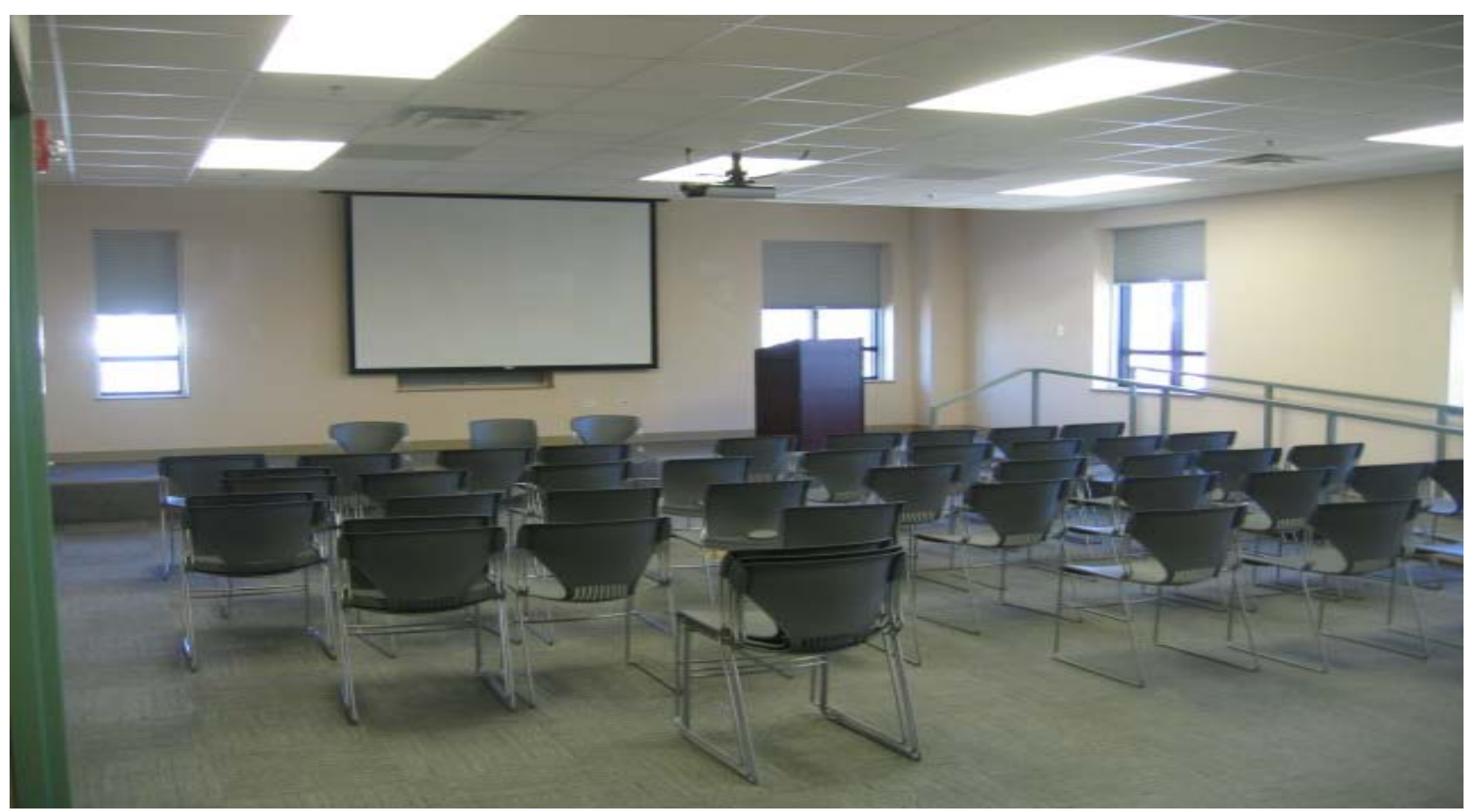

Figure 10 Community Education and Conference Room 